\title{
Preoperative anxiety predicted the incidence of postoperative delirium in patients undergoing total hip arthroplasty: a prospective cohort study
}

Jun Ma ${ }^{1,2}$, Chuanyao Li $i^{2}$, Wei Zhang ${ }^{2}$, Ling Zhou ${ }^{1,2}$, Shuhua Shu², Sheng Wang ${ }^{2}$, Di Wang ${ }^{2}$ and Xiaoqing Chai ${ }^{*}$

\begin{abstract}
Background: Delirium was characterized with a series of symptoms of a sudden onset of disturbances in attention, a loss in memory loss and defects in other cognitive abilities that were also appeared in the syndrome of anxiety. Even though there are overlapped clinical symptoms existed in anxiety and delirium, the relationship between anxiety and delirium was still unclear. The propose of this study was to investigated the effect of preoperative anxiety on postoperative delirium.
\end{abstract}

Methods: Three hundred and seventy-two adults undergoing total hip arthroplasty were enrolled from October 2019 to May 2020 in the study. The preoperative anxiety was measured with the Hospital Anxiety and Depression Scale-Anxiety (HADS-A). The participants were allocated into anxiety group (HADS-A $\geqq 7$ ) and non-anxiety group (HADS-A $<7$ ). The primary outcome was the incidence of the postoperative delirium assessed with the Confusion Assessment Method (CAM). The secondary outcomes were the duration and the severity of delirium evaluated with the Memorial Delirium assessment Scale (MDAS). The risks of delirium were also evaluated with logistic regression analysis.

Results: There were 325 patients enrolled in the end, 95 of whom met the criteria for anxiety. The incidence of delirium was $17.8 \%$ in all participants. The patients with anxiety had a higher incidence of delirium than the nonanxiety patients ( $25.3 \%$ vs. $14.8 \%$, odds ratio $(O R)=0.51,95 \%$ confidence interval $(C l)=0.92-0.29, p=0.025$ ). However, no significant differences were found in the duration and the severity of the delirium between the above two groups. The age, alcohol abuse, history of stroke, scores of the HADS-A, and education level were considered to be predictors of delirium.

Conclusions: The preoperative anxiety predicted the incidence of the postoperative delirium in total hip arthroplasty patients. The related intervention may be a good point for delirium prophylaxis.

Trial registration: It was registered at Chinese Clinical Trial Registry (www.chictr.org.cn) with the name of "the effect of preoperative anxiety on the postoperative cognitive function" (ChiCTR1900026054) at September 19, 2019.

Keywords: Anxiety, Delirium, Cognitive ability, Hip surgery

\footnotetext{
*Correspondence: xiaoging_chai@163.com

${ }^{2}$ Department of Anesthesiology, The First Affiliated Hospital of USTC, Hefei 230001, Anhui, China

Full list of author information is available at the end of the article
}

\section{$\triangle B M C$}

(c) The Author(s). 2021 Open Access This article is licensed under a Creative Commons Attribution 4.0 International License, which permits use, sharing, adaptation, distribution and reproduction in any medium or format, as long as you give appropriate credit to the original author(s) and the source, provide a link to the Creative Commons licence, and indicate if changes were made. The images or other third party material in this article are included in the article's Creative Commons licence, unless indicated otherwise in a credit line to the material. If material is not included in the article's Creative Commons licence and your intended use is not permitted by statutory regulation or exceeds the permitted use, you will need to obtain permission directly from the copyright holder. To view a copy of this licence, visit http://creativecommons.org/licenses/by/4.0/ The Creative Commons Public Domain Dedication waiver (http://creativecommons.org/publicdomain/zero/1.0/) applies to the data made available in this article, unless otherwise stated in a credit line to the data. 


\section{Background}

The postoperative delirium (POD), defined as a sudden onset of disturbances in attention, consciousness and other cognitive abilities, was one of the common surgical complications with bad outcomes. It not only had a closed relationship with other postoperative complications, such as the cognitive impairment, the high incidence of the death after surgery [1,2], but also increased the burden of the community, including high expensive health expense and more medical resources [3-6]. Although the underling pathogenesis mechanism of delirium is ambiguous, it is of great significance to study the risk factors associated with the POD to moderate its consequences.

Many risk factors for the delirium [7-20] were reported by previous studies, including age, the educational level, anemia, operative time, alcohol abuse, physical function, medications, blood loss, infection, and cognitive function.

All the risks described above had the same character --it is hard for them to be altered by interventions that may be potentially preventive for the POD. It is more meaningful to find some risk factors that are not only specific for high-risk groups but also can be interfered for prevention. For this reason, psychiatric symptoms were a good indicator. As they had a close relation with the metabolism and function of nervous system [17, 18]. It was proved that depression was a risk factor for the POD [11, 12, 15-19, 21]. Anxiety was another psychiatric symptom in the clinical practice, which was quite common before surgery. There were several studies related to anxiety $[17-19,22]$, however, the relationship between the preoperative anxiety (POA) and the POD remained unclear. Thus, this issue needed further clarification.

Orthopedic surgery, especially hip surgery in elderly, has the high incidence of POD [23, 24], most likely due to advanced age, preoperative cognitive impairment and multiple comorbidities among these patients [25]. A total of $5-45 \%$ of orthopedic surgery patients experienced delirium [26-28]. Therefore, we planned a prospective study to clarify the relationship between the POA and the POD via orthopedic surgery. The aim of the study was to investigate whether the POA would predict the onset of POD in patients undergoing the total hip arthroplasty (THA).

\section{Methods}

\section{Setting and subjects}

Ethical approval for this study [2019-N(H)-100] was provided by the biomedicine ethics board of the University of Science and Technology of China (USTC), Hefei, China (Chairperson Professor Liu) on 5 March 2019. The study was registered at the Chinese Clinical Trial
Registry (ChiCTR) with the number of ChiCTR1900026054. We consecutively recruited people aged 18 years or older, ASA I-III, undergoing the THA at the Anhui Provincial Hospital (AHPH) from October 2019 to May 2020. We excluded individuals who (1) were unable to provide written informed consent, (2) were not fluent in Chinese, (3) had a history of depression or diagnosed with depression (assessed with the Hospital Anxiety and Depression Scale-Depression [15] and diagnosed by psychiatrists), (4) had dementia or scored 24 or lower on the Mini-mental State Examination (MMSE) [15, 29], or (5) had a score of 15 or higher on the Alcohol Use Disorders Identification Test [30, $31]$, (6) not evaluated the level of anxiety, (7) not completed the follow-up assessment of delirium. The informed consent was written by all participants.

\section{Demographic and clinical characteristics}

We collected information about participant demographics (age, sex, BMI, and education), lifestyle (alcohol abuse, cigarette smoking). And the clinical characteristics were obtained from the clinical medical chart, including surgery sites and co-morbidity.

\section{Preoperative anxiety}

The anxiety was assessed using the Hospital Anxiety and Depression Scale-Anxiety (HADS-A), as it was described before [32-34]. Briefly, it was a self-reported instrument consisting of 7 items and a 4 points Likert-scale with score ranged from 0 to 21 . The severity of anxiety increased in participants with high scores in the HADS-A test. The cut-off point of HADS-A was 6/7 according to the previous study [34]. The participants with scores less than 7 were grouped in the non-anxiety group. And those with score at 7 and more were diagnosed as clinical anxiety and allocated into the anxiety group. The participants were blinded to the criteria and the grouping information.

\section{Postoperative delirium}

The incidence of delirium was the primary outcomes of the trial. Participants were assessed twice daily (in the morning and afternoon) during the first 7 postoperative days by trained researchers and nurses who administered the Confusion Assessment Method (CAM). The assessment included a review of the patients file and discussion with their allocated ward nurse and a close relative (if available). The participants who screened positive for delirium were assessed by an experienced geriatric psychiatrist to confirm. The researchers and nurses conducted the assessment of delirium after surgery were blinded to the information about grouping. The CAM is a widely used and well-validated screening tool for delirium [35-37], with sensitivity of $94 \%$ (95\% confidence 


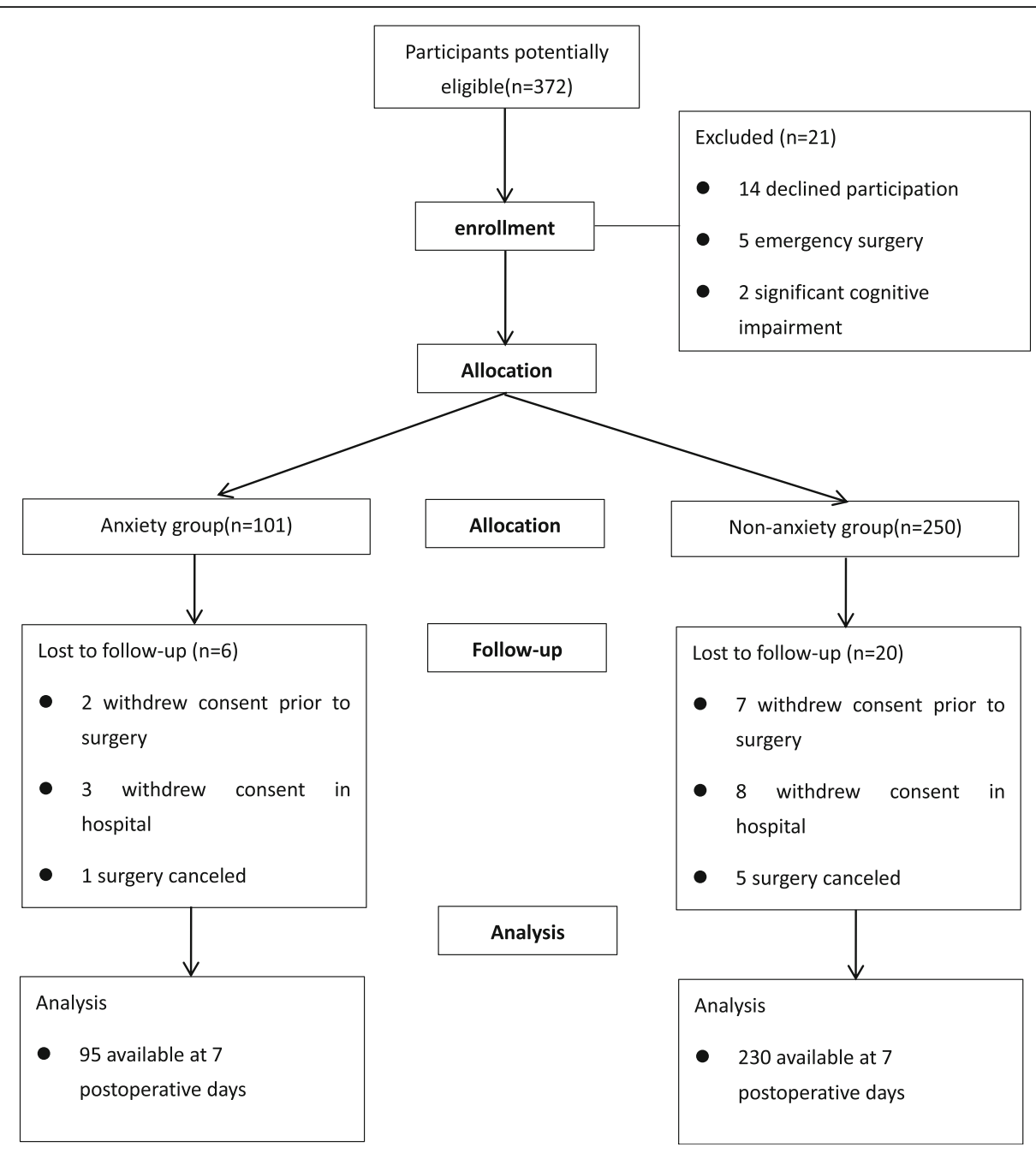

Fig. 1 Flow of participants in the trial

interval $[\mathrm{CI}]=91-97 \%)$ and specificity of $89 \%(95 \% \mathrm{CI}=$ 85-94\%) and has been successfully adapted for use in the intensive care unit (ICU) setting (the CAM-ICU was used where appropriate) [38].

\section{Other risk factors of POD}

Secondary measures of interest included the difference between groups in the duration and severity of delirium as well as length of stay (LOS) and cognitive function. The Memorial Delirium Assessment Scale (MDAS) was performed to assess the severity of delirium [39] and was administered daily if delirium was present (range $=0$ 30). The duration of delirium and LOS were measured by the number of days.

\section{Procedure}

We consecutively recruited participants who were admitted to the AHPH for the THA. The demographic data, life style, clinical characteristics, MMSE were recorded on admission by the trained research assistant with patients interview and chart review. Then we assessed the level of the anxiety in the afternoon of the day before surgery with the HADS-A [22]. The general anesthesia was performed in all participants. The surgical procedures were provided by one surgical team to avoid the bias from surgical procedures. The surgeons and anesthesiologists were blinded to the information about grouping. The assessment of the delirium was performed on the first 7 days after surgery as well as the duration and the severity. In participants with the development of the delirium, the severity was assessed using the MDAS and the duration was measured by days.

\section{Statistical analysis}

On the basis of the previous study [40] report that postoperative delirium occurred in $1.18 \%$ in age 50 s of patients after orthopedic surgery, and given the prevalence of delirium of $13 \%$ which was the highest rate in the 
study. With significance and power set at 0.05 and $90 \%$ respectively, the sample size of 94 patients was required to detect differences in each group. Of 95 patients in the anxiety group and 230 patients in the non-anxiety group were enrolled in the study.

The software of IBM SPSS statistics 25 was used to manage and analyze the data. Descriptive statistics were used to summarize data according to the allocation. Missing data from the cases not assessing anxiety and delirium were deleted from the analysis. We performed Student's $t$ test for normally distributed data, the MannWhitney $U$ test for ordinal data without a normal distribution, and $x^{2}$ tests for proportion distributions to compare the anxiety group and non-anxiety group. $p$ value $<$ 0.05 was considered statistically significant.

Variables that achieved significance on uni-variate logistic regression analysis were entered into multivariate logistic regression analysis to estimate the risk of postoperative delirium. The multiple logistic regression analysis was used to adjust for multiple risk factors and interactions. Odds ratio (OR) and 95\% confidence interval (CI) were presented to evaluate risk factors.

\section{Results}

Samples

A total of 372 individuals undergoing the THA enrolled in the study. They were allocated into the anxiety group and non-anxiety group according to the HADS-A test except 21 people (14 declined participation, 5 emergency surgery, 2 significant cognitive impairment). Six people in the anxiety group and 20 in the non-anxiety group withdrew consent or lost to follow-up during the study. Finally, there were 325 participants available at 7 postoperative days, including 95 in the anxiety group and 230 in the non-anxiety group (Fig. 1). The follow-up time was ended at 7 June 2020 due to the cognitive assessment at 7 th postoperative day.

\section{Baseline characteristics}

The prevalence of the anxiety in patients undergoing the THA was $29.2 \%$ of all 325 participants. The baseline characteristics of the participants, including demographic data, life style, and clinical characteristics were shown in Table 1 . No differences were found in all variables in the Table 1.

Table 1 Baseline characteristics of 325 adults allocated to anxiety or non-anxiety groups

\begin{tabular}{|c|c|c|c|}
\hline Characteristic & Anxiety group $(n=95)$ & Non-anxiety group $(n=230)$ & $p$ value \\
\hline \multicolumn{4}{|l|}{ Demographic data } \\
\hline Age in yrs., mean (SD) & $52.1(13.8)$ & $52.3(13.6)$ & 0.905 \\
\hline Male, n(\%) & $60(63.2 \%)$ & 124(53.9\%) & 0.126 \\
\hline $\mathrm{BMI}$ in kg/m², mean (SD) & 27.9(3.6) & $27.2(3.1)$ & 0.079 \\
\hline Education, completed high school or better, n(\%) & $38(40.0 \%)$ & $77(33.5 \%)$ & 0.263 \\
\hline \multicolumn{4}{|l|}{ Lifestyle } \\
\hline Alcohol abuse, n(\%) & $10(10.5 \%)$ & $20(8.7 \%)$ & 0.604 \\
\hline Ever smoked, n(\%) & $27(28.4 \%)$ & $70(30.4 \%)$ & 0.718 \\
\hline Current smoked, n(\%) & $33(34.7 \%)$ & $68(29.6 \%)$ & 0.360 \\
\hline \multicolumn{4}{|l|}{ Clinical characteristics } \\
\hline History of stroke, n(\%) & $16(16.8 \%)$ & $43(18.7 \%)$ & 0.693 \\
\hline $\mathrm{HD}, \mathrm{n}(\%)$ & $37(38.9 \%)$ & $84(36.5 \%)$ & 0.681 \\
\hline Hypertension, n(\%) & $42(44.2 \%)$ & $95(41.3 \%)$ & 0.629 \\
\hline Diabetes, n(\%) & $34(35.8 \%)$ & $74(32.2 \%)$ & 0.529 \\
\hline Which side of total hip arthroplasty, n(\%) & & & 0.796 \\
\hline left & $46(48.4 \%)$ & $115(50.0 \%)$ & \\
\hline right & $49(51.6 \%)$ & $115(50.0 \%)$ & \\
\hline ASA, $n(\%)$ & & & 0.803 \\
\hline । & $8(8.4 \%)$ & $15(6.5 \%)$ & \\
\hline$\|$ & 19(20.0\%) & $44(19.3 \%)$ & \\
\hline III & $68(71.6 \%)$ & $171(74.3 \%)$ & \\
\hline MMSE before surgery, mean (SD) & $27.5(1.9)$ & $27.1(2.2)$ & 0.122 \\
\hline NSAIDs, n(\%) & 75(78.9\%) & $167(72.6 \%)$ & 0.233 \\
\hline
\end{tabular}

The two groups were allocated according to the HADS-A (people of the HADS-A $\geq 7$ in the anxiety group and people of the HADS 7 in the non-anxiety group) Abbreviations: BMI Body Mass Index, IHD Ischemic Heart Disease, ASA American Society of Anesthesiologists, MMSE Mini-Mental State Examination, SD Standard Deviation, NSAIDs Non-steroidal Anti-inflammatory Drugs 


\section{Primary outcomes}

The incidence of the POD was $19.6 \%$ of all 325 participants. It was higher in patients with anxiety than those without clinical anxiety (25.3\% vs. $14.8 \%$, OR $0.51,95 \%$ CI $0.92-0.29, p=0.025)$, indicating that the factor of preoperative anxiety predicted the incidence of delirium (Table 2).

\section{Secondary outcomes}

The duration and severity of the POD had no statistical differences between two groups $(p=0.518$ and $p=0.397$, respectively). However, the LOS were longer in the POD patients with anxiety than the POD patients without anxiety [7.8(3.0) vs. 6.4(1.6), $p=0.025]$. No differences were found in the other variables between two groups (Table 2).

\section{Postoperative outcomes in all participants}

Table 3 showed the postoperative variables in all participants of the study. The LOS was significantly longer in the anxiety participants than those without clinical anxiety $(p=0.038)$, suggesting that the POA might prolong the recovery time from the surgery due to the longer length of stay. There were no statistical differences in the other variables between those two groups, including admitting to ICU, transfusion, surgery time, and other postoperative complications.

\section{Delirium risk factors}

The logistic regression model was performed to find the predictors of the POD. The age, alcohol abuse, history of stroke, scores of the HADS-A, and education level were considered to be the predictors of the POD, identifying by a multivariate logistic regression model. Surgery time, BMI, and VAS scores were not statistically significant in this model (Table 4).

\section{Discussion}

All participants undergoing the THA were assessed with the HADS-A test in the trial. The result showed that the POA might predict the incidence of POD. However, the POA seems not to affect the duration and severity of the POD. The participants with POA were fragile after surgery due to the longer length of stay in hospital.

In order to clarify the relationship between POA and POD, the other factors, such as the emergency surgery and the history of cognitive impairment, that might interfere with the results had been strictly controlled in this case-study. Additionally, the alcohol and smoke use, education level, pain and the surgery time, which might affect the incidence of the POD, were recorded and showed no statistical differences.

The factor of POA predicted the incidence of POD in the study. In consistence with Saho's study [22], they found that POA strongly predicted POD in cancer patients, which was confirmed our conclusion. The main

Table 2 Primary and secondary outcomes: complete case analysis

\begin{tabular}{|c|c|c|c|c|}
\hline Primary Outcome & $\begin{array}{l}\text { All enrolled patients }(n= \\
325)\end{array}$ & $\begin{array}{l}\text { Anxiety group }(n= \\
95)\end{array}$ & $\begin{array}{l}\text { Non-anxiety group }(n= \\
230)\end{array}$ & $\begin{array}{l}p \\
\text { value }\end{array}$ \\
\hline Incidence of delirium, n(\%) & $58 / 325(17.8 \%)$ & $24 / 95(25.3 \%)$ & $34 / 230(14.8 \%)$ & 0.025 \\
\hline Secondary Outcome & Delirium cases $(n=58)$ & $\begin{array}{l}\text { Anxiety } \\
(n=24)\end{array}$ & Non-anxiety $(n=34)$ & \\
\hline Duration of delirium $>2$ days, $n(\%)$ & $19(32.8 \%)$ & $9(37.5 \%)$ & $10(29.4 \%)$ & 0.518 \\
\hline Severity of delirium $\geqq 13, n(\%)$ & $28(48.3 \%)$ & $10(41.7 \%)$ & $18(52.9 \%)$ & 0.397 \\
\hline Patterns of delirium & & & & 0.334 \\
\hline hyperactive, n(\%) & 16 & 5 & 11 & \\
\hline hypoactive, n(\%) & 32 & 16 & 16 & \\
\hline Mix, n(\%) & 10 & 3 & 7 & \\
\hline $\begin{array}{l}\text { Age in yrs., } \\
\text { mean (SD) }\end{array}$ & $60.5(10.6)$ & $60.8(11.5)$ & $60.2(10.1)$ & 0.834 \\
\hline Male, n(\%) & $33(56.9 \%)$ & $14(58.3 \%)$ & $19(55.9 \%)$ & 0.853 \\
\hline BMI i $n$ kg/m² mean (SD) & $28.0(3.7)$ & $28.5(3.7)$ & $27.6(3.8)$ & 0.373 \\
\hline $\begin{array}{l}\text { Education, completed high school or better, } \\
\mathrm{n}(\%)\end{array}$ & $9(15.5 \%)$ & $5(20.8 \%)$ & $4(7.0 \%)$ & 0.568 \\
\hline MMSE before surgery, mean (SD) & $27.5(2.0)$ & $27.9(1.7)$ & $27.1(2.1)$ & 0.129 \\
\hline VAS, mean (SD) & $2.4(1.5)$ & $2.1(1.2)$ & $2.6(1.6)$ & 0.201 \\
\hline Surgery time in min, mean (SD) & $81.2(31.4)$ & 88.3(31.8) & $76.3(30.6)$ & 0.153 \\
\hline LOS in days, mean (SD) & $7.0(2.4)$ & $7.8(3.0)$ & $6.4(1.6)$ & 0.025 \\
\hline
\end{tabular}

Abbriviations: BMI Body Mass Index, MMSE Mini-Mental State Examination, VAS Visual Analogue Scale, LOS Length of Stay, SD Standard Deviation 
Table 3 Postoperative outcomes in two groups

\begin{tabular}{llll}
\hline Variables & Anxiety group $(\boldsymbol{n}=\mathbf{9 5})$ & Non-anxiety group $(\boldsymbol{n}=\mathbf{2 3 0})$ & $\boldsymbol{p}$ value \\
\hline Transfusion, $\mathbf{n}(\%)$ & $12 / 95(12.6 \%)$ & $32 / 230(13.9 \%)$ & 0.759 \\
ICU, $\mathbf{n}(\%)$ & $8 / 95(8.4 \%)$ & $33 / 230(14.3 \%)$ & 0.588 \\
Hypotension, $\mathbf{n}(\%)$ & $10 / 95(10.5 \%)$ & $12 / 230(5.2 \%)$ & 0.083 \\
Hematoma, $\mathbf{n}(\%)$ & $2 / 95(2.1 \%)$ & $7 / 230(3.0 \%)$ & 0.639 \\
Nausea, $\mathbf{n}(\%)$ & $20 / 95(21.1 \%)$ & $60 / 230(26.1 \%)$ & 0.338 \\
Vomiting, $\mathbf{n}(\%)$ & $9 / 95(9.5 \%)$ & $38 / 230(16.5 \%)$ & 0.100 \\
Hypothermia, $\mathbf{n}(\%)$ & $11 / 95(11.6 \%)$ & $16 / 230(7.0 \%)$ & 0.170 \\
VAS,mean (SD) & $2.7(1.6)$ & $2.9(1.7)$ & 0.445 \\
Surgery time, min, & $75.4(29.0)$ & $80.0(33.7)$ & 0.239 \\
mean (SD) & & $6.2(1.8)$ & 0.038 \\
LOS, mean (SD) & $6.8(2.6)$ & & \\
\hline
\end{tabular}

Hypotension, the blood pressures were low above $30 \%$ of the baseline or need constrictor support;

Hematoma, the data collected from postoperative clinical records or re-operation for hemostasis;

VAS Visual Analogue Scale, which was assessed at the first postoperative day, MMSE Mini-Mental State Examination, LOS Length of Stay, SD Standard Deviation

difference between two studies was the time of anxiety. For the cancer patients usually had been threaten by death, they were more likely to be anxiety or even depressed after diagnosis. This situation lasted for a long time. However, the patients undergoing THA in our study had a few threats from death. They usually felt anxiety or stress in the day before surgery, even though they had endured pain when moved. On the other hand, Van Grootven reported the POA was not associated with the POD in a retrospective study of hip fracture patients [19]. Additionally, Detroyer also found no relationship between the two conditions in cardiac surgery patients [15]. However, the limitations were found in the studies, such as a retrospective study design [19] and the fact that the delirium evaluators were not psychiatric experts [15]. In this prospective study, every delirium case was confirmed by the skillful geriatric psychiatrist. Moreover, it was also proved in the multivariable logistic regression model, in which anxiety, age, alcohol abuse, education level and stroke history were detected as predictors that were also reported in some researches [26, 41, 42]. As anxiety was a quite common symptom before surgery. Our findings suggested that the POA may be a new indicator for the POD prophylaxis [22].

To explore the exact mechanism, we hypothesized that the inflammatory cytokines may be involved. It is reported that peripheral inflammatory cytokines migrate to the central nervous system and interact with microglia, causing neuroinflammation and the subsequent development of delirium [43-45]. Similarly, the pathway was also involved in the process of anxiety [46, 47], therefore, resulting from the increased release of inflammatory cytokines in central nervous system, the POA could be a good predictor for the POD.

There were several limitations in this study. First of all, the related mechanism was not explored during the trial. This study was aimed to confirm the relationship between the POA and the POD. The underlying mechanism will be investigated in our next step. Secondly, this is the single center trial with small sample size. A multi-center randomized controlled study was required to confirm the issue. Thirdly, the randomization was hard to performed in the study. As all participants should be categorized according to

Table 4 Results of the multivariable logistic regression model predicting postoperative delirium

\begin{tabular}{llll}
\hline Variables & All participants $(\boldsymbol{n}=\mathbf{3 2 5})$ & OR(95\%Cl) & $p$ valve \\
\hline Surgery time, mean (SD) & $78.7(32.4)$ & $1.003(0.993-1.012)$ & 0.573 \\
Age, mean (SD) & $52.2(13.7)$ & $1.041(1.009-1.074)$ & 0.012 \\
BMI, mean (SD) & $27.4(3.3)$ & $1.022(0.922-1.133)$ & 0.681 \\
Alcohol abuse, $\mathbf{n}(\%)$ & $30(9.2 \%)$ & $3.414(1.299-8.975)$ & 0.013 \\
History of stroke, $\mathbf{n}(\%)$ & $59(18.2 \%)$ & $2.330(1.079-5.032)$ & 0.031 \\
Scores of the HADS-A, mean (SD) & $6.6(3.2)$ & $1.104(1.010-1.208)$ & 0.030 \\
Education level, $\mathbf{n}(\%)$ & $115(35.4 \%)$ & $0.399(0.170-0.935)$ & 0.034 \\
VAS, mean (SD) & $2.8(1.7)$ & $0.976(0.808-1.178)$ & \\
\hline
\end{tabular}

Abbreviations: BMI Body Mass Index, VAS Visual Analogue Scale, HADS-A the Hospital Anxiety and Depression Scale-Anxiety 
the HADS results. However, the control and the double blind was performed to reduce the bias in the study.

\section{Conclusions}

In conclusion, the POA predicted the incidence of POD in patients undergoing total hip arthroplasty. The related intervention may be a good point for delirium prophylaxis.

\begin{abstract}
Abbreviations
HADS-A: The Hospital Anxiety and Depression Scale-Anxiety; CAM: The Confusion Assessment Method; MDAS: The Memorial Delirium Assessment Scale; OR: Odds Ratio; Cl: Confidence Interval; POD: The Postoperative Delirium; POA: The Preoperative Anxiety; THA: The total Hip Arthroplasty; USTC: The University of Science and Technology of China; ChiCTR: The Chinese Clinical Trial Registry; AHPH: The Anhui Provincial Hospital; MMSE: The Mini-mental State Examination; LOS: Length Of Stay; BMI: Body Mass Index; IHD: Ischemic Heart Disease; ASA: American Society of Anesthesiologists; VAS: Visual Analogue Scale; SD: Standard Deviation
\end{abstract}

\section{Acknowledgements}

the surgical team of Professor Shang and Professor Zhu finished the surgery procedures of all participants in this study. We appreciated their great help and assistance

\section{Authors' contributions}

$X C$ was responsible for the design of the study and revised the manuscript. He was responsible for the included and excluded cases. SS and SW carried out the protocol in the study. JM and WZ assessed the level of anxiety before surgery and the delirium after surgery. $C L$ and $L Z$ collected the data and were blinded to the patients' allocation. JM also performed the statistical analysis and drafted the manuscript with DW. All authors read and approved the final manuscript.

\section{Funding}

The Youth Program of National Natural Science Foundation of China (No. 81503080), the Youth Program of Anhui Provincial Natural Science Foundation (No. 1608085QH210) and the Anhui Provincial Key Research and Development Project Foundation (No. 1804 h08020286) funded this work.

\section{Availability of data and materials}

The datasets used and/or analyzed during the current study are available from the corresponding author for reasonable request. And the datasets will be available at www.chictr.org.cn in 6 months after publication.

\section{Ethics approval and consent to participate}

Ethical approval for this study [2019-N(H)-100] was provided by the biomedicine ethics board of the University of Science and Technology of China (USTC), Hefei, China (Chairperson Prof. Liu) on 5 March 2019. The informed consent was written by all participants.

\section{Consent for publication}

Not Applicable.

\section{Competing interests}

All authors declared no conflict of interest.

\section{Author details}

${ }^{1}$ Anhui Provincial Hospital, Cheeloo College of Medicine, Shandong University, Jinan 250012, Shandong, China. 'Department of Anesthesiology, The First Affiliated Hospital of USTC, Hefei 230001, Anhui, China.
Received: 13 November 2020 Accepted: 8 February 2021

Published online: 12 February 2021

\section{References}

1. Marcantonio E, Flacker J, Michaels M, et al. Delirium is independently associated with poor functional recovery after hip fracture. J Am Geriatr Soc. 2000:48(6):618-24.

2. Ely EW, Shintani A, Truman B, et al. Delirium as a predictor of mortality in mechanically ventilated patients in the intensive care unit. JAMA. 2004; 291(14):1753-62.

3. van den Boogaard M, Schoonhoven L, Evers AW, et al. Delirium in critically ill patients: impact on long-term health-related quality of life and cognitive functioning. Crit Care Med. 2012:40(1):112-8.

4. Pandharipande PP, Girard TD, Jackson JC, et al. Long-term cognitive impairment after critical illness. N Engl J Med. 2013:369(14):1306-16.

5. Pisani MA, Kong SY, Kasl SV, et al. Days of delirium are associated with 1year mortality in an older intensive care unit population. Am J Respir Crit Care Med. 2009;180(11):1092-7.

6. Saczynski JS, Marcantonio ER, Quach L, et al. Cognitive trajectories after postoperative delirium. N Engl J Med. 2012;367(1):30-9.

7. Hempenius L, Slaets JP, van Asselt DZ, et al. Interventions to prevent postoperative delirium in elderly cancer patients should be targeted at those undergoing nonsuperficial surgery with special attention to the cognitive impaired patients. Eur J Surg Oncol. 2015:41(1):28-33.

8. Shah S, Weed HG, He X, et al. Alcohol-related predictors of delirium after major head and neck Cancer surgery. Arch Otolaryngol Head Neck Surg. 2012;138(3):266-71.

9. van Meenen LC, van Meenen DM, de Rooij SE, et al. Risk prediction models for postoperative delirium: a systematic review and meta-analysis. J Am Geriatr Soc. 2014;62(12):2383-90.

10. Kalisvaart KJ, Vreeswijk R, de Jonghe JF, et al. Risk factors and prediction of postoperative delirium in elderly hip-surgery patients: implementation and validation of a medical risk factor model. J Am Geriatr Soc. 2006;54(5):817-22.

11. Leung JM, Sands LP, Mullen EA, et al. Are preoperative depressive symptoms associated with postoperative delirium in geriatric surgical patients? J Gerontol A Biol Sci Med Sci. 2005;60(12):1563-8.

12. Smith PJ, Attix DK Weldon BC, et al. Executive function and depression as Independect risk factors for postoperative delirium. Anesthesiology. 2009;110(4):781-7.

13. Serafim RB, Dutra MF, Saddy F, et al. Delirium in postoperative nonventilated intensive care patients: risk factors and outcomes. Ann Intensive Care. 2012;2(1):51-6.

14. Cohen M. Depression, anxiety, and somatic symptoms in older cancer patients: a comparison across age groups. Psychooncology. 2014;23(2):151-7.

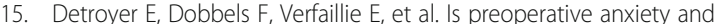
depression associated with onset of delirium after cardiac surgery in older patients? A prospective cohort study. J Am Geriatr Soc. 2008:56(12):2278-84.

16. Smith PJ, Attix DK, Weldon BC, et al. Depressive symptoms and risk of postoperative delirium. Am J Geriatr Psychiatry. 2016;24(3):232-8.

17. Bowman AM. The relationship of anxiety to development of postoperative delirium. J Gerontol Nurs. 1992;18(1):24-30.

18. Simpson CJ, Kellett JM. The relationship between pre-operative anxiety and post-operative delirium. J Psychosom Res. 1987;31(4):491-7.

19. Van Grootven B, Detroyer E, Devriendt E, et al. Is preoperative state anxiety a risk factor for postoperative delirium among elderly hip fracture patients? Geriatr Gerontol Int. 2016:16(8):948-55.

20. van der Zanden V, Beishuizen SJ, Scholtens RM, et al. The effects of blood transfusion on delirium incidence. J Am Med Dir Assoc. 2016;17(8):748-53.

21. Ghoneim MM, O'Hara MW. Depression and postoperative complications: an overview. BMC Surg. 2016:16:5

22. Wada S, Inoguchi H, Sadahiro R, et al. Preoperative anxiety as a predictor of delirium in Cancer patients: a prospective observational cohort study. World J Surg. 2019;43(1):134-42.

23. Poeran J, Cozowicz C, Zubizarreta N, et al. Modifiable factors associated with postoperative delirium after hip fracture repair: an age-stratified retrospective cohort study. Eur J Anaesthesiol. 2020;37:649-58.

24. Halaas NB, Blennow $K$, Idland A-V , et al. Neurofilament light in the serum and cerebrospinal fluid of hip fracture patients with delirium. Dement Geriatr Cogn Disord. 2018:46:346-57.

25. Yang $Y$, Zhao $X$, Dong $T$, et al. Risk factors for postoperative delirium following hip fracture repair in elderly patients: a systematic review and meta-analysis. Aging Clin Exp Res. 2017;29(2):115-26. 
26. Yang $Y$, Zhao X, Gao L, et al. Incidence and associated factors of delirium after orthopedic surgery in elderly patients: a systematic review and metaanalysis. Aging Clin Exp Res. 2020. https://doi.org/10.1007/s40520-020-01 674-1.

27. Berggren D, Gustafson Y, Eriksson B, et al. Postoperative confusion after anesthesia in elderly patients with femoral neck fractures. Anesth Analg. 1987;66(6):497-504.

28. Williams-Russo P, Urquhart BL, Sharrock NE, et al. Post-operative delirium: predictors and prognosis in elderly orthopedic patients. J Am Geriatr Soc. 1992:40(8):759-67.

29. Molloy DW, Alemayehu E, Roberts R. Reliability of a standardized minimental state examination compared with the traditional mini-mental state examination. Am J Psychiatry. 1991;148:102-5.

30. Moreta-Herrera R, Rodas JA, Lara-Salazar M. Factor validity of alcohol use disorders identification test (AUDIT) using robust estimations in ecuadorian adolescents. Alcohol Alcohol. 2020:1-9. https://doi.org/10.1093/alcalc/a gaa126.

31. Sauders JB, Aasland OG, Babor TF, et al. Development of the alcohol use disorders identification test (AUDIT): WHO collaborative project on early detection of persons with harmful alcohol consumption-II. Addiction. 1993; 88:891-04. https://doi.org/10.1111/j.1360-0443.1993.tb02093.x.

32. Akira K, Tatsuo A, Toru O, et al. Screening for psychological distress in Japanese cancer patients. Jpn J Clin Oncol. 1998;28(5):333-8.

33. Snaith R, Zigmond A. The hospital anxiety and depression scale. Br Med J (Clin Res Ed). 1986;292(6516):344.

34. Yang $Y$, Ding $R, H u D$, et al. Reliability and validity of a Chinese version of the HADS for screening depression and anxiety in psycho-cardiological outpatients. Compr Psychiatry. 2014;55(1):215-20.

35. O'Mahony R, Murthy L, Akunne A, et al. Synopsis of the national institute for health and clinical excellence guideline for prevention of delirium. Ann Intern Med. 2011;154(11):746

36. Wong $\mathrm{CL}$, Holroyd-Leduc J, Simel DL, et al. Does this patient have delirium? value of bedside instruments. JAMA. 2010;304(7):779-86.

37. Wei LA, Fearing MA, Sternberg EJ, et al. The confusion assessment method: a systematic review of current usage. J Am Geriatr Soc. 2008:56(5):823-30.

38. Ely EW, Margolin R, Francis J, et al. Evaluation of delirium in critically ill patients: validation of the confusion assessment method for the intensive care unit (CAM-ICU). Crit Care Med. 2001;29(7):1370-9.

39. Breitbart W, Rosenfeld B, Roth $A$, et al. The memorial delirium assessment scale. J Pain Symptom Manag. 1997;13(3):128-37.

40. Song K, Ko J, Kwon T, et al. Etiology and related factors of postoperative delirium in orthopedic surgery. Clinics Orthopedic Surgery. 2019;11(3):297301.

41. Low S, Wee E, Dorevitch M. Impact of place of residence, frailty and other factors on rehabilitation outcomes post hip fracture. Age Ageing. 2020. https://doi.org/10.1093/ageing/afaa131.

42. Yang Q, Wang J, Huang X, et al. Incidence and risk factors associated with postoperative delirium following primary elective total hip arthroplasty: a retrospective nationwide inpatient sample database study. BMC Psychiatry. 2020:20(1):343-52.

43. Inouye SK, Westendorp RGJ, Saczynski JS. Delirium in elderly people. Lancet. 2014;383(9920):911-22

44. Vasunilashorn SM, Ngo L, Inouye SK, et al. Cytokines and postoperative delirium in older patients undergoing major elective surgery. J Gerontol A Biol Sci Med Sci. 2015;70(10):1289-95.

45. Hoogland IC, Houbolt C, van Westerloo DJ, et al. Systemic inflammation and microglial activation: systematic review of animal experiments. J Neuroinflammation. 2015;12:114.

46. Furtado M, Katzman MA. Neuroinflammatory pathways in anxiety, posttraumatic stress, and obsessive compulsive disorders. Psychiatry Res. 2015;229(1-2):37-48.

47. O'Donovan A, Hughes BM, Slavich GM, et al. Clinical anxiety, cortisol and interleukin-6: evidence for specificity in emotion-biology relationships. Brain Behav Immun. 2010;24(7):1074-7.

\section{Publisher's Note}

Springer Nature remains neutral with regard to jurisdictional claims in published maps and institutional affiliations.

Ready to submit your research? Choose BMC and benefit from:

- fast, convenient online submission

- thorough peer review by experienced researchers in your field

- rapid publication on acceptance

- support for research data, including large and complex data types

- gold Open Access which fosters wider collaboration and increased citations

- maximum visibility for your research: over $100 \mathrm{M}$ website views per year

At BMC, research is always in progress.

Learn more biomedcentral.com/submissions 